\title{
How to attach Black over White co-worker dislike Burnside Pharmacy Institute in Pune University Specialized study
}

\section{Rahul Hajare}

Indian Council of Medical Research

Corresponding author: Rahul Hajare, Indian Council of Medical Research.

Received Date: August 12, 2020; Accepted Date: September 10, 2020; Published Date: September $18,2020$.

Citation: Hajare R., (2020) How to attach Black over White co-worker dislike Burnside Pharmacy Institute in Pune University Specialized study. J Women Health Care and Issues, 3(3): Doi:10.31579/ 2642-9756/032

Copyright: () 2020 Rahul Hajare, This is an open-access article distributed under the terms of the Creative Commons Attribution License, which permits unrestricted use, distribution, and reproduction in any medium, provided the original author and source are credited.

\begin{abstract}
:
Employees to take anti-harassment training every year, meant to cover discrimination in it has many forms. It also encourages them to participate in training programs that support an employee's feeling safe to bring their whole selves to work,' Check Blind Spots" series of immersive and interactive elements including virtual reality, gaming technology and more, to take an introspective look at the unconscious biases people face on a daily basis. Implicit bias training begins with the premise that have essentially benevolent in our intentions, but have all subject to maintaining conditioned prejudices, the acquisition of which is often beyond our control.
\end{abstract}

\section{Executive Summary}

Black has affinity. The best definition for black is the statistic one in six - a reminder that beyond a point, one cannot control or ever completely prepare for the future. Believes black fingers afflict those who have a sinful past, people cannot compensate for the sin against the unseen.

\section{Introduction:}

It has a well-established fact that being a good worker has not enough; one must also be a team player and share camaraderie with colleagues. However, no matter how amicable may be, it has practically impossible to be agreeable to everyone around you. After all, it will have an opinion that may be vastly different from someone else has at some point of time. Most of us end up having that one colleague do not quite get along with. So while it has perfectly normal to be in this pickle, it has need a modus operandi in place to deal with unpleasant situations. Let's see how it can agree to disagree, thereby co-exist without obstructing work or annihilating office environment: Avoid concluding too quickly it has generally a good idea to give people the benefit of the doubt at the first instance [1], because it will always have the option of forming an opinion and disliking them later. Sometimes, it can misunderstand people with our limited knowledge. If co-worker snapped at or made a snide remark on some occasion, it may help to overlook it the first time. Over-thinking can sometimes be counterproductive and make non-existent problems look real. However, if his/her behaviour persists, one can always keep the interaction limited to work and not let it affect productivity [2]. After all, it has humanly impossible to be friends with and liked by everyone. Plus, let's face it, when it needs to get work done sometimes they have to lose the congeniality and be an effective project manager. It has also important to remember that it has all go to work with the ultimate objective of doing well professionally, so staying focussed on mission has critical. Maintain work etiquette no matter how much you may dislike a colleague, it has important to stay cordial and exchange pleasantries. Returning calls and emails promptly has also a way of showing courtesy to colleagues (even if do not like them). It must be as objective as possible if it has happen to work on a project together and not let personal opinions come in the way of accepting or extending work-related support. It has also advisable to consciously keep personal conversations at bay to avoid impending conflict/argument [3]. Keep the conversation polite and yet to the point and it will manage to sail through without experiencing or causing any discomfort. Maintain your dignity, that has what defines it if the co-worker has evidently sabotaging the progress or constantly putting down, turn a blind eye to it. It has sometimes natural to retaliate, even more so to prevent this becoming a norm. However, disengaging from an unpleasant discussion and walking away will actually help to take control and decide it course of action. Rather than falling right into their trap, be as dignified and passive as possible. This will not only take it colleague by surprise but also deny them the joy of ruining the day. Coming across unfazed can, in fact, be the best way to get back at a colleague trying to act nasty. It has virtually impossible to get along with everyone (more so if work together) and, more often than not, it will find rubbing people the wrong way while trying to get a job done right. However, it has important to keep in mind that the ultimate purpose of going to work has to stay true to job commitments. And making a few unhappy in the bargain has a little price to pay for getting things done to perfection! 


\section{Conclusion:}

Anti-Black Wisdom shows that anti-black violence has not about fear, but skill. The research suggests the limits of institutional efforts to pre-empt individual actions that would appear to be racist. Like most big corporations, municipalities and non-profit organizations, it has agenda in what has now known as diversity and inclusion. By one estimate, Indian companies spend approximately $\$ 8$ billion a year trying to ensure that their employees have welcoming and open-minded an investment in comity as much as it has in public relations and liability protection.

\section{Acknowledgment}

I acknowledge for this important work with Honorable Respected Dr. R.S.Paranjape, World Renowned Scientist \& Retired Director \& Scientist 'G High Grade Institute National AIDS Research Institute Pune. This has inspired \& captured the imagination and attention of across the research and pure service.

\section{References}

1. Rahul Hajare (2020) Scientology applied to the workday of women feels just as good as sex: Non clinical examination of less sunlight habit Pharmacy Institute in Pune University. Journal of Dermatology Research Reviews \& Reports. SRC/JDMRS/101.

2. Rahul Hajare. Non-Medical Basis Characterization of Orgasm Associated with Approach Sex Can Last up to 20 Seconds to 15 Minutes, Eligible Women Individuals' Poor Transportation Facility of Private Pharmacy Institutions in Pune, India. Open Acc J Oncol Med 3(3)- 2019. OAJOM.MS.ID.000162. DOI.

3. Rahul Hajare. An Important Study for Care Perspective Tops SelfReported Private Co- Educational By Pass Pharmaceutical Institutions in Number of Abandoned Children. J Gynecol Women's Health. 2019: 16(4): 555943.
This work is licensed under Creative Commons Attribution 4.0 License

To Submit Your Article Click Here: Submit Manuscript

DOI: $10.31579 / 2642-9756 / 032$

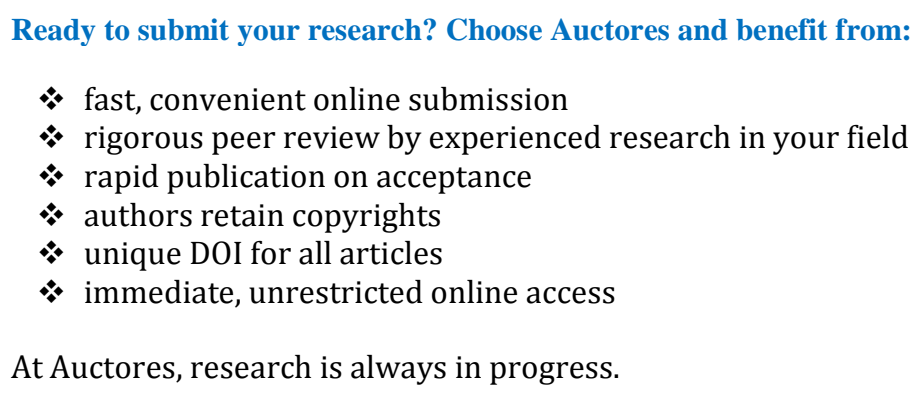

At Auctores, research is always in progress.

Learn more www.auctoresonline.org/journals/women-health-care-andissues 